\title{
SHORT COMMUNICATION \\ SCREENING OF OPPORTUNISTIC ENCEPHALITOZOON INTESTINALIS AND ENTEROCYTOZOON BIENEUSI IN IMMUNOCOMPROMISED PATIENTS IN SLOVAKIA
}

\author{
Monika Halánová1, Alexandra Valenčáková2, Pavol Jarčuška³, Miloš Halán', Ol'ga Danišová2, Ingrid Babinská1, \\ Kinga Dedinská5, Lýdia Čisláková1 \\ 'Department of Epidemiology, Faculty of Medicine, P. J. Šafárik University in Košice, Slovak Republic \\ ${ }^{2}$ Department of Biology and Genetics, University of Veterinary Medicine and Pharmacy, Košice, Slovak Republic \\ ${ }^{3}$ Department of Infectology and Travel Medicine, Faculty of Medicine, P. J. Šafárik University in Košice, Slovak Republic \\ ${ }^{4}$ Department of Epizootology and Parasitology, University of Veterinary Medicine and Pharmacy, Košice, Slovak Republic \\ ${ }^{5}$ Department of Haematology and Oncohaematology, Faculty of Medicine, P. J. Šafárik University in Košice, Slovak Republic
}

\section{SUMMARY}

Objective: In recent years new infectious diseases, i.e. emerging or re-emerging diseases, have been coming to the forefront. Currently, microsporidia, considered to be a major cause of emerging and opportunistic infections particularly in immunocompromised individuals, are also included in this group. Therefore, the aim of our study was to map the prevalence of Encephalitozoon intestinalis and Enterocytozoon bieneusi infection in a group of patients and to compare it with the occurrence of specific antigens in immunocompetent people.

Methods: Detection of spores of both pathogens in faecal samples was performed by an immunofluorescence test using species-specific monoclonal antibodies.

Results: Positivity to E. intestinalis in 91 examined immunosuppressed patients reached 33\% (30/91), while only $4.3 \%$ (3/70) of the control group samples were found to be positive (relative risk 7.7, $p<0.001$ ). In case of $E$. bieneusi $14.3 \%(13 / 91)$ of immunocompromised patients were positive, as were $5.7 \%$ (4/70) of people from the control group (relative risk $2.5, p=0.095)$.

Conclusion: In case of development of any opportunistic infection, the infection is detected and removed in most cases at an early stage. The incidence of clinically manifested microsporidiosis in patients with immunodeficiency is rare as they are under constant medical supervision. However, we must not forget about opportunistic infections, and in case of any non-specific symptoms it is necessary to exclude or confirm the diagnosis for immediate treatment.

Key words: Encephalitozoon intestinalis, Enterocytozoon bieneusi, immunocompromised patients, microsporidia, monoclonal antibodies

Address for correspondence: A. Valenčáková, Department of Biology and Genetics, University of Veterinary Medicine and Pharmacy, Komenského 73, 04181 Košice, Slovak Republic. E-mail: alexandra.valencakova@uvlf.sk

https://doi.org/10.21101/cejph.a5407

\section{INTRODUCTION}

The importance of opportunistic pathogens, which are able to be agents of disease only if the natural defence mechanisms are damaged and function of immune system is decreased, is growing due to an increasing number of patients with HIV infection/ AIDS, as well as other persons with disrupted immune systems due to primary or secondary immunodeficiency.

Microsporidia are among the opportunistic pathogens that occur with greater frequency or severity in patients with impaired host defences. They are single-celled, obligate spore-forming intracellular pathogens that infect a broad range of invertebrates and vertebrates, including humans. Based on the observation that chitin is present in the spore wall, the identification of a mitochondrial HSP70 gene and phylogenetic analyses of the genes encoding beta tubulin, a large subunit of RNA polymerase II and
TATA box binding protein, microsporidia were reclassified from protozoa to fungi $(1,2)$. Currently, 14 of approximately 1,500 named species of microsporidia have been identified as infectious agents of humans, of which Enterocytozoon bieneusi and Encephalitozoon intestinalis are the most frequently identified (3). Transmission routes depend on the species of microsporidia involved in the infection and include faecal-oral route, oral-oral route, inhalation of contaminated aerosols, ingestion of contaminated food and water, direct contact with broken skin or eyes, and sexual transmission (4). The risk factors associated with infection are not known precisely, but it is known for sure that they are very closely related to immune status. The main risk factor of human microsporidiosis is immune deficiency. People with a CD4 T-lymphocyte count below 50-100 cells per $\mathrm{mm}^{3}$ are most susceptible, and clinical signs of infection occurring in them include (depending on the species of microsporidia) 
intestinal, lung, kidney, liver, sinus, muscle or eye disease, and occasionally also infection of the central nervous system (CNS) $(4,5)$. Microsporidiosis is a cosmopolite disease. Data on prevalence have varied greatly depending on geographical locations, the population studied, sample selection technique and the diagnostic methods used $(4,6)$. In Slovakia, microsporidia infection was diagnosed and reported in animals - dogs, mice, rabbits, cows, goats, cats, sheep, pigs, and bird - and also in humans (7-19).

The diagnosis of microsporidiosis can be based directly on the presence of microsporidia spores in biological samples (stool, urine, aspirates, sputum, conjunctival swab, tissue) or indirectly by serological methods. Because detection at the species level is important for therapeutic purposes, in practice molecular methods or immunofluorescence antibody assay (IFA) are usually used (20). However, there is no study from Slovakia on the occurrence of microsporidia infection among immunosuppressed patients. Therefore, the aim of our study was to map the prevalence of $E$. intestinalis and E. bieneusi infection in immunocompromised patients and to compare it with the occurrence of specific antigens in immunocompetent people.

\section{MATERIALS AND METHODS}

\section{Study Population}

A total of 161 people were examined for the presence of the microsporidia Encephalitozoon (E.) intestinalis and Enterocytozoon (E.) bieneusi. The examined persons were divided into three groups according to their primary diagnosis and health status. In the first group were 17 patients with HIV/AIDS aged 23-63 years $($ mean $=40.29, \mathrm{SD}=9.63)$ registered at the AIDS centre in L. Pasteur University Hospital in Košice. The patients were at different stages of the disease - from A1 to $\mathrm{C} 3$ according to the CDC classification system. The second group included 74 patients with compromised immune systems due to underlying disease and associated illnesses in a regular haemodialysis programme. Patients were aged $34-79$ years $($ mean $=64.21, \mathrm{SD}=9.56)$. The third group included 70 clinically healthy individuals aged 1-72 (mean $=26.31, \mathrm{SD}=20.17)$, who attended periodic preventive check-ups and who have not been reported any signs that could point to a possible infection. None of these persons had been diagnosed for microsporidiosis even in the past.

\section{Samples}

Freshly collected stool samples obtained from the examined people during the study conducted in 2011 were stored at $-20^{\circ} \mathrm{C}$ in the dark without any conservation until processed.

\section{Detection of Enterocytozoon bieneusi and Encepha- litozoon intestinalis by IFA Using Specific Monoclonal Antibodies}

Detection of E. bieneusi and E. intestinalis antigen in stool samples was done with a commercial immunofluorescence test (Bordier Affinity products, CH-1023 Crissier, Switzerland) using specific E. bieneusi resp. E. intestinalis monoclonal antibodies.
Faecal samples were diluted $(1: 2)$ with phosphate-buffer saline (PBS pH7.2) and filtered through a $50 \mu \mathrm{m}$ filter. Slides with 18 -wells were prepared by depositing $2 \mu \mathrm{L}$ of the diluted faecal samples into each well and air drying them at room temperature for an hour. The slides were then fixed with methanol for a few seconds, left to air dry and subsequently dipped for 10 minutes in acetone at $-20^{\circ} \mathrm{C}$ and again left to air dry. Each well was rehydrated with a drop of PBS and left for five minutes at room temperature. The PBS was aspirated and each well was covered with $20 \mu \mathrm{L}$ of monoclonal antibodies; the slides were incubated for 30 minutes at room temperature in a moist chamber in the dark. They were then washed three times with PBS and each well was covered with $20 \mu \mathrm{L}$ of conjugated fluorescein isothiocyanate (FITC) and incubated for 30 minutes in a moist chamber in the dark. The conjugate was then aspirated and the slide washed three times with PBS and dried. Cover slips were mounted with anti-fading fluorescence mounting medium in the wells, and the slides were examined using a fluorescent microscope. The smears were examined at $1,000 \times$ magnification with ultra-violet light. In case of a positive result, the spores were shown as oval, brightly fluorescent formations of approximately $1.3 \times 0.7 \mu \mathrm{m}$ (E. bieneusi), or $1.7 \times 1.1 \mu \mathrm{m}$ (E. intestinalis).

\section{Statistical Analysis}

Basic descriptive statistics were used for the analysis of obtained results. Relative risk (RR) and their 95\% confidence intervals $(95 \% \mathrm{CI})$ were estimated for the occurrence of microsporidia E. intestinalis and E. bieneusi. All tests were considered significant at $\mathrm{p}<0.05$.

\section{Ethics Statement}

Oral informed consent was obtained from every person or legal representative prior to examination.

\section{RESULTS}

Of the total number of 161 stool samples examined by IFA, $33(20.5 \%)$ showed positivity for E. intestinalis and 17 (10.6\%) for E. bieneusi (Table 1). Positive cases were observed in all the tested groups.

A prevalence of $17.6 \%$ (3/17) for E. intestinalis and 23.5\% (4/17) for E. bieneusi were observed in patients in the first group HIV/AIDS (Table 2), and a prevalence of 36.5\% (27/74) for E. intestinalis and $12.2 \%(9 / 74)$ for E. bieneusi were observed in patients in a regular haemodialysis programme, respectively. The lowest positivity rates $-4.3 \%(3 / 70)$ for E. intestinalis and $5.7 \%(4 / 70)$ for E. bieneusi - were detected in the third control group of healthy individuals (Table 1).

Upon comparing the relative risk of occurrence of E. intestinalis and $E$. bieneusi infection between the individual groups, the risk of $E$. intestinalis infection was found to be more than 4-times higher in the group of HIV/AIDS patients than in the control group (RR 4.11, 95\% CI 0.90-18.64, p=0.06). Higher relative risk for the HIV/AIDS patients was also detected in case of E. bieneusi infection (RR 4.12, 95\% CI 1.14-14.81, p=0.03) (Table 1). 
Table 1. Influence of immunodeficiency on positivity to E. intestinalis and E. bieneusi $(N=161)$

\begin{tabular}{|c|c|c|c|c|}
\hline & $\begin{array}{c}\text { Positive } \\
\text { n (\%) }\end{array}$ & RR & $95 \% \mathrm{Cl}$ & $\mathrm{p}$-value \\
\hline \multicolumn{5}{|l|}{ E. intestinalis } \\
\hline Control group $(n=70)$ & $3(4.3)$ & ref. & & \\
\hline HIVIAIDS patients $(n=17)$ & $3(17.6)$ & 4.11 & $0.90-18.64$ & 0.06 \\
\hline Haemodialysis patients $(n=74)$ & $27(36.5)$ & 8.5 & $2.70-26.81$ & $<0.001^{*}$ \\
\hline HIVIAIDS and haemodialysis patients $(n=91)$ & $30(33.0)$ & 7.7 & $2.44-24.17$ & $<0.001^{*}$ \\
\hline \multicolumn{5}{|l|}{ E. bieneusi } \\
\hline Control group $(n=70)$ & $4(5.7)$ & ref. & & \\
\hline HIVIAIDS patients $(n=17)$ & $4(23.5)$ & 4.12 & $1.14-14.81$ & $0.03^{*}$ \\
\hline Haemodialysis patients $(n=74)$ & $9(12.2)$ & 2.13 & $0.69-6.60$ & 0.191 \\
\hline HIVIAIDS and haemodialysis patients $(n=91)$ & $13(14.3)$ & 2.5 & $0.85-7.33$ & 0.095 \\
\hline
\end{tabular}

$\mathrm{RR}$ - relative risk; $\mathrm{Cl}$ - confidence interval; *statistically significant

Table 2. Prevalence of $E$. intestinalis and E. bieneusi in patients with HIVIAIDS $(N=17)$

\begin{tabular}{|c|c|c|c|c|c|c|}
\hline AIDS stage & Gender & Year of birth & Viral load & $\begin{array}{l}\text { Number of CD4 } \\
\text { T cells/ } / \mu L \text { blood }\end{array}$ & E. intestinalis & E. bieneusi \\
\hline $\mathrm{A} 1$ & Female & 1982 & Undetectable & 520 & - & - \\
\hline A2 & Female & 1977 & Undetectable & 477 & - & - \\
\hline A2 & Male & 1978 & Undetectable & 610 & - & - \\
\hline A2 & Male & 1968 & Undetectable & 460 & - & - \\
\hline A2 & Male & 1974 & Undetectable & 424 & - & + \\
\hline A2 & Male & 1972 & Undetectable & 422 & - & + \\
\hline B1 & Male & 1981 & Undetectable & 565 & - & - \\
\hline B1 & Male & 1988 & 26.000 & 460 & - & - \\
\hline B2 & Male & 1975 & Undetectable & 490 & + & - \\
\hline B2 & Male & 1969 & 11.000 & 310 & - & - \\
\hline B3 & Female & 1966 & Undetectable & 412 & - & - \\
\hline C3 & Female & 1966 & Undetectable & 133 & + & - \\
\hline C3 & Female & 1969 & Undetectable & 240 & - & + \\
\hline C3 & Male & 1965 & Undetectable & 192 & + & - \\
\hline C3 & Male & 1956 & Undetectable & 181 & - & - \\
\hline $\mathrm{C} 3$ & Male & $1956 \dagger$ & 55.000 & 90 & - & + \\
\hline C3 & Male & 1948 & Undetectable & 280 & - & - \\
\hline
\end{tabular}

Upon comparing the relative risk of positive cases of $E$. intestinalis and E. bieneusi between the group of patients in a regular haemodialysis programme (Group 2) and the control group (Group 3) a higher risk was found in both types of infection for patients from Group 2 (E. intestinalis RR 8.5, 95\% CI 2.7-26.8, p $<0.001$; E. bieneusi RR 2.1, 95\% CI 0.68-6.59, p=0.19) (Table 1).

Generally, upon comparing the relative risk of occurrence of $E$. intestinalis and $E$. bieneusi infection between immunosuppressed and immunocompetent patients groups, the risk was found to be more than 7-times higher for the immunosuppressed patients in case of E. intestinalis infection (RR 7.7, 95\% CI 2.44-24.17, $\mathrm{p}<0.001)$ and 2.5-times higher in case of E. bieneusi infection (RR 2.5, 95\% CI 0.85-7.33, p=0.095) (Table 1).

\section{DISCUSSION}

Microsporidia as newly emerging pathogens are responsible for infection of the major animal groups and are considered to be a cause of emerging and opportunistic infections in humans.

Although the first human case of microsporidiosis was reported in 1959 (21), until the beginning of the AIDS pandemic in the 1980 s, microsporidia were identified only rarely (22). Since then, the number of cases has been constantly increasing not only in persons with HIV/AIDS, but also in other immunocompromised patients, such as organ transplant recipients, patients with malignant diseases, patients with cytomegalovirus infection, persons with congenital deficiency in immunoglobulins or with diabetes. 
In immunocompetent people infection is occurring in travellers, children, the elderly, and wearers of contact lenses $(23,24)$.

In our study the immunofluorescence antibody test for species-specific diagnosis of intestinal microsporidiosis detected E. bieneusi antigen in four patients with HIV/AIDS. Two of them had a CD4 lymphocyte count of 424 and 422, respectively, at the time of diagnosis of microsporidiosis. Both patients are homosexuals living in a common household. One of the risk factors associated with microsporidiosis that supports horizontal transmission also includes homosexual practices (25), but the definitive proof of this way of transmission needs to be confirmed after genotyping, based on clinical history of these two people. Another two patients were in the $\mathrm{C} 3$ stage of HIV/AIDS and the level of CD4+ lymphocytes ranged below 100, and 200, respectively (Table 2).

In case of $E$. intestinalis antigen detection, two of the three patients from our study were at stage $\mathrm{C} 3$ (the level CD4 + cells was below 200 for both), which is characterized, inter alia, by the occurrence of opportunistic infections. Another positive patient was in stage B2 (level of CD4 + lymphocytes below 499) (Table 2).

The results in patients with HIV infection/AIDS drawn from this study (with a positive result, or $17.6 \%$ and $23.5 \%$, respectively) correlated with most of the results obtained by other authors. In general, prevalence of microsporidia infection in this group of patients ranged between $1.2 \%$ and $78 \%$, with the average of $15 \%(4,26)$.

The second part of the group of immunocompromised patients in our study consisted of patients in a regular haemodialysis programme, in which the immunodeficiency occurs due to a complication of the underlying disease, such as e.g., malnutrition, hypovitaminosis or recurrent infections. Suppression or improper functioning of the immune system causes an increase in the pathogenic effects of the microbes. Of the 74 samples examined in this group, $36.5 \%$ were positive to E. intestinalis and $12.2 \%$ to E. bieneusi. Concurrent infection with E. intestinalis and $E$. bieneusi was observed in six cases (8.1\%). Generally, the haemodialysis procedure per se as well as disturbances in both innate and adaptive immunity makes haemodialysis patients susceptible to infection $(27,28)$, which is a major cause of morbidity and the second most common cause of death in this group (28). Parasites (including microsporidia) are one of the major groups of pathogens that play an important role in creating complications in patients with renal problems, which are especially affected by cellular immunity (29). The clinical manifestation of the disease depends on the species of the pathogen and the immune status of the host. If clinical symptoms develop, enteritis, cholangitis, cholecystitis, rhinitis, sinusitis, pneumonia, and bronchitis are typical for E. bieneusi and E. intestinalis, and in case of E. intestinalis nephritis and disseminated infection as well.

For comparison, we also examined 70 clinically healthy individuals, who showed $4.3 \%$ positivity to $E$. intestinalis and $5.7 \%$ positivity to E. bieneusi. According to previously published results the prevalence rates for microsporidia infection in immunocompetent people ranged from $0 \%$ to $86 \%(4,30)$. These results show that immunocompetent people are routinely exposed to microsporidia, but infection is often asymptomatic or self-limited.

The diagnostic methods used in our study appear to be appropriate to clinical practice. They have high sensitivity and specificity; monoclonal antibodies are highly species-specific, which eliminates the chances of cross reactivity with other spe- cies, pathogens or faecal debris (20). PCR-based methods are increasingly employed in research laboratories for species-specific and genotype-specific identification but are still not routinely applied in diagnostic laboratories because of the requirement for a reference laboratory, skilled technical staff and standardization $(20,31)$, as well as the price of reagents and equipment. In contrast to this, IFA is affordable, and its advantages are its ability to give a result within approximately 2.5 hours and its use for epidemiologic surveys.

\section{CONCLUSION}

Based on our obtained results, we can conclude that the observed risk of opportunistic infections, namely microsporidiosis caused by E. intestinalis and E. bieneusi, is higher in immunodeficient patients compared to the healthy population. On the other hand, immunodeficient patients in our medical conditions are under constant medical supervision and have unrestricted access to adequate treatment not only of the underlying disease, but also associated infections and complications. In case of development of any opportunistic infection, the infection is in most cases detected and eliminated in the initial stage, therefore, clinically manifested microsporidiosis is rarely present. Despite these facts, opportunistic infections should not be forgotten in this group of patients, and in case of any non-specific symptoms it is necessary to exclude or confirm the diagnosis with the aim of immediate treatment in case of a positive result.

\section{Conflict of Interests}

None declared.

\section{Acknowledgements}

The study was supported by the Slovak Grant Committee VEGA, Grant No. 1/0084/18 and APVV-15-0134.

\section{REFERENCES}

1. Fast NM, Logdson JM Jr, Doolittle WF. Phylogenetic analysis of the TATA box binding protein (TBP) gene from Nosema locustae: evidence for a microspridia-fungi relationship and spliceosomal intron loss. Mol Biol Evol. 1999;16(10):1415-9.

2. Keeling PJ, Fast NM. Microsporidia: Biology and evolution of highly reduced intracellular parasites. Ann Rev Microbiol. 2012;56:93-116.

3. Didier ES, Weiss LM. Overview of microsporidia and microsporidiosis. Protistology. 2008;5(4):243-55.

4. Didier ES, Stovall ME, Green LC, Brindley PJ, Sestak K, Didier PJ. Epidemiology of microsporidiosis: sources and modes of transmission. Vet Parasitol. 2004;126(1-2):145-66.

5. Matos O, Lobo EL, Xiao L. Epidemiology of Enterocytozoon bieneusi infection in humans. J Parasitol Res. 2012;2012:981424. doi:10.1155/2012/981424.

6. Didier ES, Weiss LM. Microsporidiosis: current status. Curr Opin Infect Dis. 2006;19(5):485-92.

7. Adam J, Valencakova A, Halanova M, Danisova O, Gorbarova K, Cislakova L. Serological screening of selected microsporidia in HPV-positive women. Acta Parasitol. 2015;60(1):50-3.

8. Čisláková L, Literák I, Bálent P, Hipíková V, Levkutová M, Trávniček M, et al. Prevalence of antibodies to Encephalitozoon cuniculi (Microsporidia) in Angora goats - potential risk of infection for breeders. Ann Agric Environ Med. 2001;8(2):289-91.

9. Čisláková L, Schréter I, Jarčuška P. Microsporidian infection in a patient with AIDS. Klin Mikrobiol Infekc Lek. 1998;4(6):184-5. (In Slovak.) 
10. Danisova O, Valencakova A, Stanko M, Luptákova L, Hasajova A. First report of Enterocytozoon bieneusi and Encephalitozoon intestinalis infection of wild mice in Slovakia. Ann Agric Environ Med. 2015;22(2):251-2.

11. Halánová M, Letková V, Macák V, Štefkovic M, Halán M. The first finding of antibodies to Encephalitozoon cuniculi in cows in Slovakia. Vet Parasitol. 1999;82(2):167-71.

12. Halánová M, Čisláková L, Valenčákova A, Bálent P, Adam J, Trávniček M. Serological screening of occurrence of antibodies to Encephalitozoon cuniculi in humans and animals in eastern Slovakia. Ann Agric Environ Med. 2003;10(1):117-20.

13. Halánová M, Valenčáková A, Malčeková B, Kváč M, Sak B, Květoňová $\mathrm{D}$, et al. Occurrence of microsporidia as emerging pathogens in Slovak Roma children and their impact on public health. Ann Agric Environ Med. 2013;20(4):695-8.

14. Luptáková L, Petrovová E. The occurrence of microsporidial infections and toxoplasmosis in Slovak women. Epidemiol Mikrobiol Imunol. 2011;60(4):156-60.

15. Malčeková B, Valenčáková A, Luptáková L, Molnár L, Ravaszová P, Novotný F. First detection and genotyping of Encephalitozoon cuniculi in a new host species, gyrfalcon (Falco rusticolus). Parasitol Res. 2011;108(6):1479-82.

16. Malčeková B, Valenčáková A, Molnár L, Kočišová A. First detection and genotyping of human-associated microsporidia in wild waterfowl of Slovakia. Acta Parasitol. 2013;58(1):13-7.

17. Valenčáková A, Bálent P, Petrovová E, Novotný F, Luptáková L. Encephalitozoonosis in household pet Nederland Dwarf rabbits (Oryctolagus cuniculus). Vet Parasitol. 2008;153(3-4):265-9.

18. Valenčáková A, Bálent P, Húska M, Novotný F, Luptáková L. First case report of infections caused by Encephalitozoon intestinalis in swine in Europe. Acta Vet Hung. 2006;54(3):407-11.

19. Valenčáková A, Bálent P, Ravaszová P, Horák A, Oborník M, Halánová $\mathrm{M}$, et al. Molecular identification and genotyping of Microsporidia in selected hosts. Parasitol Res. 2012;110(2):689-93.

20. Ghoshal U, Khanduja S, Pant P, Ghoshal UC. Evaluation of immunofluorescence antibody assay for the detection of Enterocytozoon bieneusi and Encephalitozoon intestinalis. Parasitol Res. 2016;115(10):3709-13.
21. Matsubayashi H, Koike T, Mikata I, Takei H, Hagiwara S. A case of Encephalitozoon-like-body infection in man. AMA Arch Pathol. 1959;67(2):181-7.

22. Canning EU, Lom J. The Microsporidia of vertebrates. London: Academic Press; 1986.

23. Didier ES, Weiss LM. Microsporidiosis: not just in AIDS patients. Curr Opin Infect Dis. 2011;24(5):490-5.

24. Didier ES. Microsporidiosis: an emerging and opportunistic infection in humans and animals. Acta Trop. 2005;94(1):61-76.

25. Dascomb K, Frazer T, Clark RA, Kissinger P, Didier E. Microsporidiosis and HIV. J Acquir Immune Defic Syndr. 2000;24(3):290-2.

26. Espern A, Morio F, Miegeville M, Illa H, Abdoulaye M, Meyssonnier V, et al. Molecular study of microsporidiosis due to Enterocytozoon bieneusi and Encephalitozoon intestinalis among human immunodeficiency virusinfected patients from two geographical areas: Niamey, Niger, and Hanoi, Vietnam. J Clin Microbiol. 2007;45(9):2999-3002.

27. Eleftheriadis T, Kartsios C, Yiannaki E, Kazila P, Antoniadi G, Liakopoulos V, et al. Chronic inflammation and CD16+ natural killer cell zeta-chain downregulation in hemodialysis patients. Blood Purif. 2008;26(4):317-21.

28. Eleftheriadis T, Liakopoulos V, Leivaditis K, Antoniadi G, Stefanidis I. Infection in hemodialysis: a concise review - Part 1: bacteremia and respiratory infections. Hippokratia. 2011;15(1):12-7.

29. 39. Karadag G, Tamer GS, Dervisoglu E. Investigation of intestinal parasites in dialysis patients. Saud Med J. 2013;34(7):714-8.

30. Sak B, Brady D, Pelikánová M, Květoňová D, Rost M, Kostka M, et al. Unapparent microsporidial infection among immunocompetent humans in the Czech Republic. J Clin Microbiol. 2011;49(3):1064-70.

31. Garcia LS. Laboratory identification of the Microsporidia. J Clin Microbiol. 2002;40(6):1892-901.

Received April 20, 2018 Accepted in revised form August 27, 2019 